\title{
Serological and Immunohistochemical Detection of Helicopacter pylori Infection among Egyptian Hepatitis C Virus Patients
}

\author{
Hany M. Ibrahim ${ }^{1}$, Rabie E. El Shaer ${ }^{2,3}$, Ibrahim A. El Elaimy ${ }^{1}$ and \\ Ramzy M. Rabea ${ }^{1,3}$ \\ ${ }^{1}$ Immunology \& Physiology Unit, Zoology Department, Faculty of Science, Menoufia University, \\ Shibin El Kom, Egypt, \\ ${ }^{2}$ Pathology Department, Faculty of Medicine, Al-Azhar University, Egypt, \\ ${ }^{3}$ Liver and Heart Institute, Kafer El Shiekh, Egypt.
}

Corresponding Author Hany M. Ibrahim, Ph.D

Mobile:

+02-0100-3689245

\section{E mail:}

hany.mohamed@scien ce.menofia.edu.eg hanyibrahimeg@gmail .com

Running title: Detection of H. pylori in HCV Egyptian patients

Key words: Helicobacter, Hepatitis $C$, Co-infection, ELISA Immunohistochemistry, Egypt
Background and study aim: Helicobacter pylori infection is distributed worldwide. $H$. pylori colonize the liver and increase the severity of the liver pathogenesis. The aim of the present study was to detect the $H$. pylori in the HCV patients using serology and immunohistochemistry diagnostic methods. The aim was extended to evaluate the hematological and biochemical changes during the co-infection.

Materials and Methods: ELISA and immunohistochemistry diagnostic methods were utilized to examine patients chronically infected with $\mathrm{HCV}$ for $H$. pylori, and some hematological and biochemical parameters were detected.

Results: Overall prevalence of $H$. pylori infection was $10.81 \%, 8.00 \%$, using ELISA, and immunohistochemistry, respectively. In the current study, no significant difference based on gender, residence, age, biochemical assessment and HCV RNA load was observed. Liver cirrhosis at patient coinfected with $H$. pylori and HCV recorded high percentage compared to those with chronic HCV mono-infection. A significant increase in the relative lymphocyte count was detected in patients with concomitant $H$. pylori and chronic $\mathrm{HCV}$ infections compared to patients with chronic $\mathrm{HCV}$ mono-infection.

Conclusion: Because H. pylori infection is frequent among Egyptian HCV infected patients, regular screening and treatment for $H$. pylori among this category is extremely important.

\section{INTRODUCTION}

In 1983, a Gram-negative bacterium, Helicobacter pylori (H. pylori), was firstly discovered [1]. Despite the infection of $H$. pylori is very common in developing countries, it was distributed worldwide [2]. Colonization of $H$. pylori in the stomach is associated with many pathogenic effects in the upper gastrointestinal tract, e.g. gastric cancer, peptic ulcer disease, mucosaassociated lymphoid tissue (MALT) lymphoma and chronic gastritis [3]. Moreover, H. pylori positivity has been linked to several diseases, such as idiopathic iron deficiency anemia [4], idiopathic thrombocytopenic purpura [5], ischemic heart disease [6], autoimmune pancreatitis [7-9], acute coronary syndromes [10], and hepatobiliary diseases [11-13].
Recent reviews have collected data emphasized the capability of $H$. pylori to induce and increase the severity of the liver pathogenesis $[\mathbf{1 , 1 4 ]}$. Previous reports tried to explain how $H$. pylori colonize the liver. Some manuscripts clarified that upon the occurring of portal hypertension during the later stages of chronic liver disease, $H$. pylori could trans-located from the stomach into the blood through the portal system and then the bacteria DNA could be detected in the liver tissues [15-17]. Other reports mentioned that the $H$. pylori might use macrophages or circulating retrograde transfer from the duodenum to reach the liver [18]. In vitro studies using the human hepatic cell line (HepG2) emphasized the cytopathic effect of $H$. pylori in the damage of the hepatocytes $[\mathbf{1 9 , 2 0 ]}$. The bacteria might exert its pathological 
effect on HepG2 cells through the up-regulation of proteins incorporated in metabolism, signal transduction and transcription regulation [21].

Around the world hepatitis $\mathrm{C}$ virus $(\mathrm{HCV})$ affects one hundred seventy million persons and results in about five hundred thousand deaths/year [22]. The highest prevalence of HCV infection about 15\% was recorded in Egypt [23,24]. Decompensated liver cirrhosis, hepatocellular carcinoma (HCC) and liver transplantation are associated with the hepatitis that caused by HCV infection [25-27]. Esmat and his colleagues demonstrated a significant association between $H$. pylori infection and severity of liver pathology in patients with HCVrelated chronic hepatitis and cirrhosis with or without hepatocellular carcinoma [28]. Furthermore, in co-infected patients with $\mathrm{HCV}$ and $H$. pylori, more pronounced fibrosis stages and more cirrhotic nodules and impairment of hepatic parenchyma were detected than in HCV monoinfected patients [29]. Hence, the objective of the present study was to detect $H$. pylori in the $\mathrm{HCV}$ patients using serology and Immunohistochemistry diagnostic methods and evaluate the hematological and biochemical changes during the co-infection.

\section{MATERIALS AND METHODS}

\section{Ethical statement}

The present study was conducted in accordance with the Declaration of Helsinki and the Guidelines for Good Clinical Practice and approved by the ethical committee of Faculty of Medicine, Al-Azhar University and Kafer El Shiekh Liver and Heart Institute, Egypt. The purpose and procedures involved in the present study were explained and written informed consent was obtained from all participants.

\section{Study population}

One hundred eighty five patients chronically infected with HCV from Kafer El Shiekh Liver and Heart Institute, Egypt during the period between February 2015 and March 2016 were enrolled in the present study. The patients included 82 females and 103 males, with age range 20-57 with a mean of $(40.90 \pm 7.90)$ years.

The study population was divided into three groups. Group-I: 121 patients with chronic HCV infection without $H$. pylori infection. Group-II: 18 patients with concomitant $H$. pylori and chronic HCV infections serologically detected. Group-III: 8 patients with concomitant $H$. pylori and chronic HCV infections immunohistochemically detected.

\section{Exclusion criteria}

Patients with malignancy, including HCC or renal, cardiopulmonary or autoimmune disorders and pregnant women were excluded from the study.

\section{Detection of $\mathrm{HCV}$ antibodies and RNA}

$\mathrm{HCV}$ antibodies were detected by EIA (COBASAmplicore, Germany). Qualitative evaluation of HCV-RNA by PCR was performed using a commercial kit (Roche Diagnostic, Branchburg, $\mathrm{NJ}$ ) according to the manufacturer's instructions.

\section{Serological analysis of $\boldsymbol{H}$. pylori infection}

$H$. pylori IgG antibodies were determined by the qualitative ELISA test using commercially available kit (Calbiotech Inc, CA, USA). Assays were done according to the manufacturer's instructions and results of $H$. pylori IgG were expressed as index values.

\section{Immunohistochemical analysis of $H$. pylori infection}

One hundred out of $185 \mathrm{HCV}$ chronically infected patients performed a liver biopsy to investigate grading and staging of hepatic disease. In this category of patients, $H$. pylori was detected by an indirect labeling streptavidin-biotin immunohistochemistry (IHC) [30] using a rabbit anti- $H$. pylori-specific antibody (Dako, Hamburg, Germany).

\section{Hematological and biochemical analysis}

Complete blood count (CBC) was determined using an automated hematology analyzer XP series (Sysmex, Japan). Direct, total bilirubin, albumin, fasting sugar, alanine transaminase (ALT), aspartate transaminase (AST) and creatinine were run on using $\mathrm{ABX}$ Pentra $\mathrm{C} 400$ clinical chemistry analyzer (Horiba ABX SAS, Montpellier, France). Alpha-fetoprotein (AFP) and antinuclear antibody (ANA) were determined using chemiluminescent immunoassay (Liaison, DiaSorin, Germany). Thyroid-stimulating hormone (TSH) was detected using (Teco Diagnostics, CA, USA). International normalized ratio (INR) was done automatically using a commercial kit (Siemens Healthcare Diagnostic Inc., Germany). In all 185 patients, compensated cirrhosis was determined by Fibroscan $^{\mathrm{TM}}>12.5 \mathrm{kPa}$. In the HCV chronically infected patients subjected to a liver biopsy compensated cirrhosis was also determined by biopsy of METAVIR 4 or Ishak more than or equal 5. 


\section{Statistical analysis}

SPSS (IBM SPSS statistics for Windows, Armonk, NY) computer program was used for statistical analysis. Binary logistic regression was used to assess significant differences of $H$. pylori infection rate in $\mathrm{HCV}$-infected patients of different age, localities, and sex. Hematological and biochemical changes were evaluated by using ANOVA test followed by post hoc analysis of group differences that was accomplished by the least significant differences (LSD) test; $\mathrm{p}<0.05$ were considered to be statistically significant. Agreement between ELISA and immunohistochemistry was calculated according to Ibrahim et al. [31,32].

\section{RESULTS}

Helicopacter pylori infection among Egyptian $\mathrm{HCV}$ patients was summarized in Table 1. Overall prevalence was $10.81 \%$, and $8.00 \%$, using ELISA, and IHC, respectively. The seroprevalence was significantly $(\mathrm{P}<0.05)$ increased among the $\mathrm{HCV}$ patients from Gharbiya province $15.66 \%$ when compared to Kafr El Sheikh province $6.86 \%$. Similarly, IHC demonstrated significant higher levels of $H$. pylori infection among HCV patients Gharbiya province $10.53 \%$ compared to Kafr El Sheikh province $4.65 \%$. H. pylori infection was detected in the liver of $\mathrm{HCV}$ patients as represented in Fig. 1.

During the $H$. pylori detection among Egyptian $\mathrm{HCV}$ patients, the results of the ELISA were cross-tabulated with those of IHC and summarized in Table 2. Among one hundred HCV patients, the agreement percentage between the results of ELISA, and those of IHC was $96 \%$.
Table 3 demonstrated the relation between $H$. pylori positivity and age, gender, and residence among Egyptian HCV patients. According to residence, the bacteria prevalence was nonsignificantly lower $(\mathrm{P}>0.05)$ in the rural areas, $6.74 \%, 2.70 \%$ than the urban areas, $12.50 \%$, and $11.11 \%$ using ELISA and IHC, respectively. Although, higher prevalence was recorded in male and younger patients compared to female and older patients, no significant difference was detected in the prevalence of $H$. pylori among $\mathrm{HCV}$ patients based on gender and age, using ELISA, or IHC.

Characteristics of cirrhosis, HCV RNA load and biochemical data of the study population were shown in Table 4. Liver cirrhosis and at patient with concomitant $H$. pylori and chronic $\mathrm{HCV}$ infections showed a higher percentage compared to those patients with chronic HCV mono-infection. Similar patterns were detected at the levels of HCV RNA load among the study populations. Furthermore, similar patterns were detected at the levels of AFP, TSH, glucose, INR, AST, ALT, direct, total bilirubin, albumin, creatinine and ANA among the study populations.

Hematological findings of the study population were illustrated in Tables 5. Minimal significant increase $(\mathrm{P}<0.05)$ was detected in the current study, at the level of relative lymphocyte counts in patients with concomitant H. pylori and chronic HCV infections immunohistochemically detected compared to those patients with chronic HCV mono-infection. No significant alterations were determined on the levels of the other examined hematological parameters (Table 5).

Table (1) : Prevalence of Helicobacter pylori infection among HCV infected patients from Egypt using ELISA and IHC

\begin{tabular}{|c|c|c|c|c|}
\hline Regions & Total & ELISA & Total & IHC \\
\hline Kafr-elshikh & 102 & $7(6.86 \%)$ & 43 & $2(4.65 \%)$ \\
\hline Gharbiya & 83 & $13(15.66 \%)^{*}$ & 57 & $6(10.53 \%)^{*}$ \\
\hline Total & 185 & $20(10.81 \%)$ & 100 & $8(8.00 \%)$ \\
\hline
\end{tabular}

* Prevalence of $H$. pylori is significantly different ( $p<0.05$, logistic regression test). 
Table (2) : Summary on the detection of Helicobacter pylori infections

\begin{tabular}{|c|c|c|c|c|}
\hline \multirow{3}{*}{ H. pylori } & \multicolumn{2}{|c|}{ ELISA $^{\text {a }}$} & \multicolumn{2}{c|}{ IHC $^{\mathbf{b}^{\mathbf{b}}}$} \\
\cline { 2 - 5 } & $(+)$ & 12 & 8 & $(-)$ \\
\cline { 2 - 5 } & $(-)$ & 88 & 0 & 4 \\
\hline & Total & 100 & 8 & 88 \\
\hline
\end{tabular}

${ }^{a}$ The frequencies of positive and negative samples as results of ELISA.

${ }^{b}$ The frequencies of positive and negative samples as results of IHC cross-tabulated with ELISA results.

Table (3) : Socio-demographic characteristics and prevalence of Helicobacter pylori infection among HCV infected patients using ELISA and IHC

\begin{tabular}{|l|c|c|c|c|}
\hline \multicolumn{1}{|c|}{ Characteristics } & Total & ELISA & Total & IHC \\
\hline Age & & & & \\
\hline 40 year or less & 84 & $9(10.71 \%)$ & 53 & $5(9.43 \%)$ \\
\hline More than 40 & 101 & $9(8.91 \%)$ & 47 & $3(3.38 \%)$ \\
\hline Sex & & & & \\
\hline Male & 103 & $13(12.62 \%)$ & 64 & $6(9.38 \%)$ \\
\hline Female & 82 & $5(6.10 \%)$ & 36 & $2(5.56 \%)$ \\
\hline Residence & & & & \\
\hline Urban & 96 & $12(12.50 \%)$ & 63 & $7(11.11 \%)$ \\
\hline Rural & 89 & $6(6.74 \%)$ & 37 & $1(2.70 \%)$ \\
\hline
\end{tabular}

Table (4) : Characteristics of cirrhosis, HCV RNA load and biochemical data of the study population

\begin{tabular}{|l|c|c|c|}
\hline \multicolumn{1}{|c|}{ Parameter } & $\begin{array}{c}\text { Group I } \\
\text { (HCV) }\end{array}$ & $\begin{array}{c}\text { Group II } \\
\text { (HCV+ H. pylori) } \\
\text { ELISA }\end{array}$ & $\begin{array}{c}\text { Group III } \\
\text { (HCV+ H. pylori) } \\
\text { IHC }\end{array}$ \\
\hline Cirrhotic Liver & $16(13.22 \%)$ & $3(16.67 \%)$ & $2(25.00 \%)$ \\
\hline HCV RNA (10 $\mathbf{~ I U / m l ) ~}$ & $19.69 \pm 2.44$ & $20.85 \pm 6.16$ & $22.54 \pm 13.09$ \\
\hline AFP (ng/dl) & $12.45 \pm 3.17$ & $9.56 \pm 3.87$ & $2.95 \pm 0.28$ \\
\hline TSH ( $\boldsymbol{\mu l U}$ /ml) & $1.54 \pm 0.09$ & $1.27 \pm 0.19$ & $0.97 \pm 0.19$ \\
\hline Glucose (mg/dl) & $113.11 \pm 5.67$ & $93.56 \pm 4.01$ & $89.5 \pm 5.19$ \\
\hline INR & $1.08 \pm 0.01$ & $1.13 \pm 0.04$ & $1.14 \pm 0.08$ \\
\hline ANA (Negative/Positive) & $185(100 \%) / 0(0 \%)$ & $185(100 \%) / 0(0 \%)$ & $185(100 \%) / 0(0 \%)$ \\
\hline Creatinine (mg/dl) & $0.74 \pm 0.01$ & $0.73 \pm 0.03$ & $0.68 \pm 0.04$ \\
\hline Direct-Bil (g/dl) & $0.39 \pm 0.04$ & $0.27 \pm 0.03$ & $0.23 \pm 0.03$ \\
\hline T-Bil (mg/dl) & $1.01 \pm 0.06$ & $0.82 \pm 0.06$ & $0.74 \pm 0.11$ \\
\hline Albumin (g/d) & $3.94 \pm 0.04$ & $4.26 \pm 0.07$ & $4.15 \pm 0.11$ \\
\hline ALT (U/L) & $61.88 \pm 4.20$ & $56.72 \pm 16.05$ & $41.12 \pm 5.93$ \\
\hline AST (U/L) & $55.58 \pm 3.66$ & $42.83 \pm 7.60$ & $39.62 \pm 4.50$ \\
\hline
\end{tabular}

Data are expressed as: mean \pm standard error (STE) or number (\% among study population). 
Table (5) : Hematological findings of different groups

\begin{tabular}{|l|c|c|c|}
\hline \multicolumn{4}{|c|}{ Study population } \\
\hline & $\begin{array}{c}\text { Group I } \\
\text { (HCV) }\end{array}$ & $\begin{array}{c}\text { Group II } \\
\text { (HCV+ H. pylori) } \\
\text { ELISA }\end{array}$ & $\begin{array}{c}\text { Group III } \\
\text { (HCV+ H. pylori) } \\
\text { IHC }\end{array}$ \\
\hline RBCs $\times \mathbf{1 0}^{\mathbf{6}}$ & $4.83 \pm 0.09$ & $5.36 \pm 0.14$ & $5.30 \pm 0.15$ \\
\hline PCV (\%) & $41.35 \pm 0.39$ & $44.84 \pm 0.11$ & $42.50 \pm 0.01$ \\
\hline Hb (g/dl) & $13.63 \pm 0.15$ & $14.52 \pm 0.36$ & $13.60 \pm 0.59$ \\
\hline MCV (\%) & $83.69 \pm 0.55$ & $84.10 \pm 0.99$ & $80.95 \pm 1.66$ \\
\hline MCH (\%) & $27.64 \pm 0.26$ & $27.30 \pm 0.56$ & $25.82 \pm 0.89$ \\
\hline MCHC (\%) & $32.99 \pm 0.18$ & $32.46 \pm 0.50$ & $31.86 \pm 0.46$ \\
\hline Platelets $\times \mathbf{1 0}$ & $185.31 \pm 7.38$ & $203.7 \pm 14.90$ & $192.62 \pm 20.63$ \\
\hline WBCs $\times \mathbf{1 0}$ & $6.62 \pm 0.19$ & $6.61 \pm 0.45$ & $6.54 \pm 0.44$ \\
\hline Lym (\%) & $37.67 \pm 0.01$ & $39.28 \pm 0.02$ & $43.25 \pm 0.02 *$ \\
\hline Neu (\%) & $51.40 \pm 0.01$ & $50.11 \pm 0.02$ & $47.38 \pm 0.03$ \\
\hline Mon (\%) & $10.96 \pm 0.003$ & $10.33 \pm 0.01$ & $8.50 \pm 0.01$ \\
\hline
\end{tabular}

Data are expressed as: mean \pm standard error (STE). ${ }^{*} P<0.05$ indicate significant difference compared to the patients with chronic HCV mono-infection.

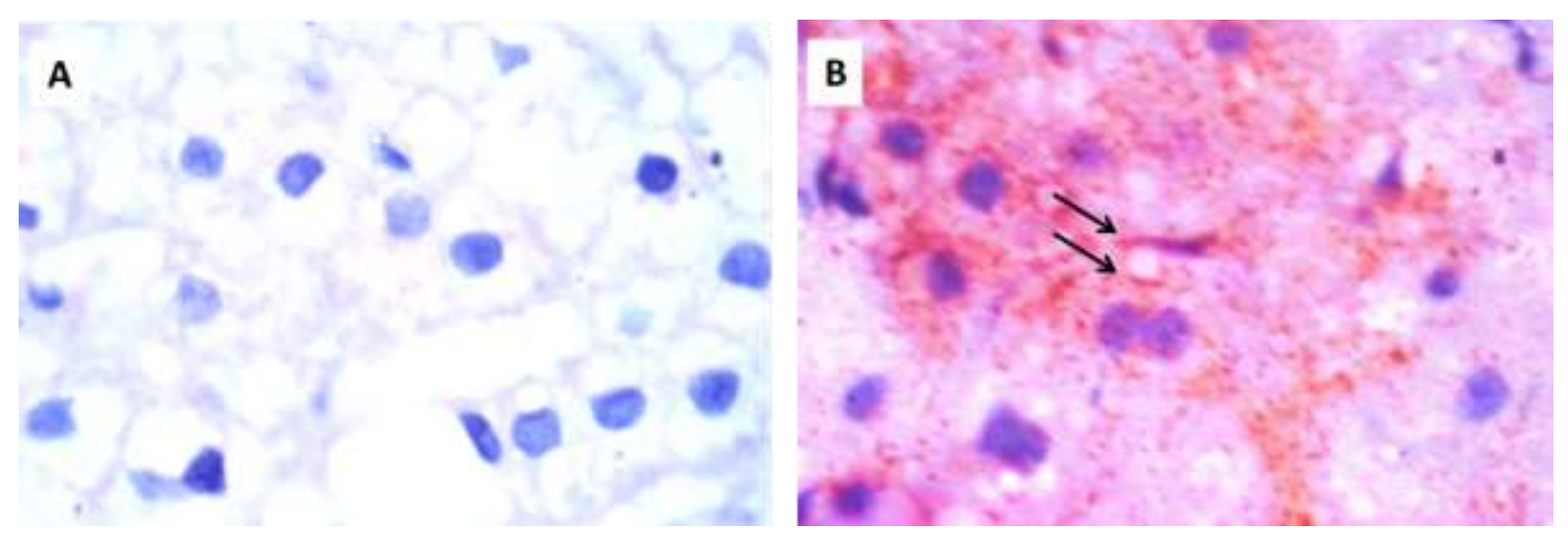

Fig. (1) : Identification of Helicobacter pylori in the liver from HCV infected patient. (A) Immunohistochemical section of the liver from $\mathrm{HCV}$ infected patient without any detection of $H$. pylori (B) Specific detection of $H$. pylori with anti- H. pylori antibody immuno-stained as a dark brown color, original magnification, $\times 1000$. 


\section{DISCUSSION}

In the current study, $H$. pylori prevalence in 185 HCV infected individuals from Gharbiya and Kafr El Sheikh provinces was examined by ELISA, and from those cases one hundred HCV infected patients were examined using IHC. The overall prevalence of $H$. pylori was $10.81 \%$, and $8.00 \%$ using ELISA, and IHC, respectively. According to the area, significant high $H$. pylori prevalence was detected among patients from Gharbiya province compared to those from Kafr El Sheikh province using ELISA, and IHC, respectively. In Tanta City the capital of Gharbiya province, high prevalence of $H$. pylori $69.4 \%$ was demonstrated among patients with different gastrointestinal symptoms [33]. Wang et al. demonstrated that $H$. pylori prevalence was significantly higher in $\mathrm{HCV}$ infected patients than in those without chronic HCV infection [34]. Previous study detected $H$. pylori antibodies and DNA prevalence $61.7 \%$ and $10 \%$, respectively, among chronic hepatitis C patients from Suez Canal areas (east of Egypt) [35]. Another Egyptian study from Alexandria, detected $76.90 \%$ H. pylori positivity in the stools of $\mathrm{HCV}$ patients using rapid test [36]. Molecular prevalence of $H$. pylori was demonstrated in $11.5 \%$ of chronic HCV patients from the Gastroenterology and Hepatology Unit of Suez Canal University Hospital [37]. Seroprevalence of $H$. pylori among $\mathrm{HCV}$ patients was $55.6 \%$ from Minufiya province, Egypt [38].

Generally, low prevalence was detected for microbes using IHC or PCR compared to serological assays. The weak reliability of the IHC assays might be rendered to low numbers of the bacteria in the tested human tissues, small sample size of the collected tissue, and may be, randomized distribution of bacterial units. Although a high agreement between the results of ELISA, and IHC was demonstrated in this study, IHC detected lower positivity than ELISA. The lower positivity detected by the microscopic examination could be attributed to the previously mentioned sampling issues. Furthermore, the antibody response is always independent of bacterial burden. Pervious report recorded a good agreement between ELISA and histopathological methods with higher ELISA detection for H. pylori [39]. Moreover, low $H$. pylori prevalence was demonstrated by nested PCR when compared to $H$. pylori antibodies using ELISA [35,37].
The $H$. pylori prevalence was higher in males, younger patients and urban area residents, however, no significant relation was demonstrated between the $H$. pylori positivity and age, gender and residence among $\mathrm{HCV}$ infected patients using ELISA and IHC. Moreover, in the current study, biochemical assessment and HCV RNA load at patient with concomitant $H$. pylori infection and chronic HCV infection was similar to patients with chronic HCV mono-infection. Several reports demonstrated that there was no statistical difference between ages, gender, liver function tests, AFP levels or viral load in the prevalence of $H$. pylori in $\mathrm{HCV}$ infected patients $[37,40,41]$.

In the current study, liver cirrhosis at patient with concomitant $H$. pylori and chronic HCV infections showed a high percentage compared to those patients with chronic HCV mono-infection. Several previous reports revealed a strong association between $H$. pylori infection and the progression of liver injuries such as cirrhosis and fibrosis

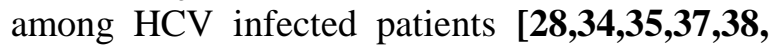
40,41].

Moreover, in the current study, a significant increase in the level of the relative lymphocyte count was detected in patients with concomitant H. pylori and chronic HCV infections compared to patients with chronic HCV mono-infection. Early report demonstrated that lymphocyte counts were increased in $H$. pylori-infected patients [42] Nagata et al. reported that lymphocyte counts were significantly elevated in $H$. pylori-infected patients compared to those in $H$. pylori-negative patients during the diagnosis of immune thrombocytopenic purpura [43].

In conclusion, the present study indicated that $H$. pylori infection is frequent in Egypt, with noticeable prevalence among HCV patients. Regular screening and treatment for $H$. pylori among HCV patients is important.

\section{Ethical approval:Approved .}

\section{Conflict of interest}

The authors declare that they have no competing interests.

\section{Acknowledgments}

The authors acknowledge the staff of the Kafer El Shiekh Liver and Heart Institute, Egypt for their valuable contributions in collecting samples. 


\section{REFERENCES}

1. Waluga M, Kukla M, Żorniak M, Bacik A, Kotulski R. From the stomach to other organs: Helicobacter pylori and the liver. World $J$ Hepatol 2015; 7(18): 2136-2146.

2. Wu MS, Lee WJ, Wang HH, Huang SP, Lin JT. A case-control study of association of Helicobacter pylori infection with morbid obesity in Taiwan. Arch Intern Med 2005; 165: 15521555.

3. Franceschi, F., Genta, R. M. \& Sepulveda, A. R. Gastric mucosa: long-term outcome after cure of Helicobacter pylori infection. J. Gastroenterol 2002; 37(13): 17-23.

4. Marignani M, Angeletti S, Bordi C, Malagnino F, Mancino C, Delle Fave G, Annibale B. Reversal of long-standing iron deficiency anaemia after eradication of Helicobacter pylori infection. Scand J Gastroenterol 1997; 32: 617-622.

5. Gasbarrini A, Franceschi F, Tartaglione R, Landolfi R, Pola P, Gasbarrini G. Regression of autoimmune thrombocytopenia after eradication of Helicobacter pylori. Lancet 1998; 352: 878.

6. Mendall MA, Goggin PM, Molineaux N, Levy J, Toosy T, Strachan D, et al. Relation of Helicobacter pylori infection and coronary heart disease. Br Heart J 1994; 71: 437-439.

7. Kountouras J, Zavos C, Chatzopoulos DA. concept on the role of Helicobacter pylori infection in autoimmune pancreatitis. $J$ Cell Mol Med 2005; 9: 196-207.

8. Guarneri F, Guarneri C, Benvenga S. Helicobacter pylori and autoimmune pancreatitis: role of carbonic anhydrase via molecular mimicry? J Cell Mol Med 2005; 9: 741-744.

9. Okazaki K, Uchida K, Fukui T. Recent advances in autoimmune pancreatitis: concept, diagnosis, and pathogenesis. J Gastroenterol 2008; 43: 409418.

10. Franceschi F, Niccoli G, Ferrante G, Gasbarrini A, Baldi A, Candelli M, et al. CagA antigen of Helicobacter pylori and coronary instability: insight from a clinico-pathological study and a meta-analysis of 4241 cases. Atherosclerosis 2009; 202(2): 535-542.

11. Ki MR, Goo MJ, Park JK, Hong IH, Ji AR, Han SY, et al. Helicobacter pylori accelerates hepatic fibrosis by sensitizing transforming growth factor- $\beta 1$-induced inflammatory signaling. $L a b$ Invest 2010; 90(10): 1507-1516.

12. Polyzos SA, Kountouras J, Papatheodorou A, Patsiaoura K, Katsiki E, Zafeiriadou E, et al. Helicobacter pylori infection in patients with nonalcoholic fatty liver disease. Metabolism 2013; 62(1): 121-126.
13. Hu BL, Wang HY, Yang GY. Association of Helicobacter pylori infection with hepatic encephalopathy risk: a systematic review. Clin Res Hepatol Gastroenterol 2013; 37(6):619-25.

14. Franceschi F, Zuccalà G, Roccarina D, Gasbarrini A. Clinical effects of Helicobacter pylori outside the stomach. Nat Rev Gastroenterol Hepatol 2014; 11(4): 234-242.

15. Casafont F, Martin L, Pons-Romero F. Bacterial overgrowth in the small intestine in chronic liver disease. In: Blum HE, Bode JC, Bode Ch, Sartor RB(ed). Gut and the liver. London: Kluwer Academic Publishers; 1998; p 332-337.

16. Tsunneyama K, Harada K, Kono N, Hiramatsu K, Zen Y, Sudo Y, et al. Scavenger cells with Gram-positive bacterial lipoteichoic acid infiltrate around the damaged interlobular bile ductus of primary biliary cirrhosis. J Hepatol 2001; 35(2): 156-163.

17. Tu QV, Okoli AS, Kovach Z, Mendz GL. Hepatocellular carcinoma: prevalence and molecular pathogenesis of Helicobacter spp. Future Microbiol 2009; 4(10): 1283-1301.

18. Queiroz DMM, Santos A. Isolation of a Helicobacter strain from the human liver. Gastroenterol 2001; 121(4): 1023-1024.

19. Taylor NS, Fox JG, Yan L. In vitro hepatotoxic factor in Helicobacter hepaticus, $H$. pylori and other Helicobacter species. J Med Microbiol 1995; 42(1): 48-42.

20. Chen R, Fan XG, Huang Y, Li N, Chen CH. In vitro cytotoxicity of Helicobacter pylori on hepatocarcinoma HepG2 cells. Al Zheng 2004; 23(1): 44-49.

21. Zhang Y, Fan XG, Chen R, Xiao ZQ, Feng XP, Tian XF, Chen ZH. Comparative proteome analysis of untreated and Helicobacter pyloritreated HepG2. World J Gastroenterol 2005; 11(22): 3485-3489.

22. Wandeler G, Dufour JF, Bruggmann P, Rauch A. Hepatitis C: a changing epidemic. Swiss Med Wkly 2015; 145: w14093.

23. Fallahian F, Najafi A. Epidemiology of hepatitis $\mathrm{C}$ in the Middle East. Saudi J Kidney Dis Transp 2011; 22(1): 1-9.

24. Guerra J, Garenne M, Mohamed MK, Fontanet A. HCV burden of infection in Egypt: results from a nationwide survey. J Viral Hepat 2012; 19: 560-567.

25. Davis GL, Albright JE, Cook SF, Rosenberg DM. Projecting future complications of chronic hepatitis $\mathrm{C}$ in the United States. Liver Transpl 2003; 9(4): 331-338.

26. El-Serag HB, Mason AC. Rising incidence of hepatocellular carcinoma in the United States. $N$ Engl J Med 1999; 340(10): 745-50. 
27. Verna EC, Brown Jr RS. Hepatitis C virus and liver transplantation. Clin Liver Dis 2006; 10(4): 919-40.

28. Esmat G, El-Bendary M, Zakarya S, Ela MA, Zalata K. Role of Helicobacter pylori in patients with HCV-related chronic hepatitis and cirrhosis with or without hepatocellular carcinoma: possible association with disease progression. $J$ Viral Hepat 2012; 19: 473-479.

29. Sakr SA, Badrah GA, Sheir RA. Histological and histochemical alterations in liver of chronic hepatitis C patients with Helicobacter pylori infection. Biomed Pharmacother 2013; 67: 367374.

30. Marzio L, Angelucci D, Grossi L, Diodoro MG, Campli ED, Cellini L. Anti-Helicobacter pylori specific antibody immunohistochemistry improves the diagnostic accuracy of Helicobacter pylori in biopsy specimen from patients treated with triple therapy. Am J Gastroenterol 1998; 93: 223-226.

31. Ibrahim HM, Abdel-Ghaffar F, Osman GY, ElShourbagy SH, Nishikawa Y, Khattab RA. Prevalence of Toxoplasma gondii in chicken samples from delta of Egypt using ELISA, Histopathology and Immunohistochemistry. $J$ Parasit Dis 2016; 40(2): 485-490.

32. Ibrahim HM, Mohamed AH, El-Sharaawy AA, El-Shqanqery HE. Molecular and serological prevalence of Toxoplasma gondii in pregnant women and sheep in Egypt. Asian Pac J Trop Med 2017; 10(10): 996-1001.

33. Sabah AA, Gneidy MR, Saleh NM. Prevalence of Helicobacter pylori infection among adult patients with different gastrointestinal parasites in Tanta City district. J Egypt Soc Parasitol 2015; 45(1): 101-106.

34. Wang J, Li WT, Zheng YX, Zhao SS, Li N, Huang $\mathrm{Y}$, et al. The Association between Helicobacter pylori Infection and Chronic Hepatitis C: A Meta-Analysis and Trial Sequential Analysis. Gastroenterol Res Prac 2016; 2016 Article ID 8780695. doi:10.1155/2016/8780695
35. Ragheb MM, Awad MM, Tag Eldeen LA, Dosoki TM. Impact of Helicobacter pylori infection on liver fibrosis in Egyptian patients with chronic hepatitis C. J Advan Res 2012; 3: 287-293.

36. Zaki NE, Nafea DA, Elbeih SM, Elsheikh WH, Ibrahim NS, Mansour AR. Does Helicobacter Pylori Co-Infection Contribute to Hepatitis C Virus-Associated Thrombocytopenia in Egyptian Patients? J Med Sci Clin Res 2016; 4 (10): 12927-12933.

37. Mahmoud MA, Tag Eldeen LA, Mohamed M. Awad MM, Haile HA. Helicobacter Pylori DNA in Liver Tissues from Chronic Hepatitis C Egyptian Patients. Gastroenterol Res 2011; 4(6): 262-267.

38. El-Masry S, El-Shahat M, Badra G, Aboel-Nour MF, Lotfy M. Helicobacter pylori and Hepatitis C Virus Coinfection in Egyptian Patients. J Global Infect Dis 2010; 2(1): 4-9.

39. Iqbal S, Fatim S, Raheem A, Khan AH. Agreement between serology and histology for detection of Helicobacter pylori infection. $J$ College Physicians Surgeons Pakistan 2013; 23(11): 784786.

40. Madkour NK, Ghanem AMS, El-melegy SYH, Abdel-Moneim MO, Abdel-Salam SS, Hussein $\mathrm{G}$, et al. Effect of Helicobacter pylori on Treatment of Hepatitis C Virus Egyptian Patients. Donnish J Biomed Res 2016; 3(2): 013-018.

41. Abd El-Salam SS, Darwish M, Elagawy W. Study the Association of Helicobacter pylori and some of Hepatitis C Virus Patients in Egypt. Egypt J Microbiol 2017; 52: 29- 37

42. Karttunen TJ, Niemelä S, Kerola T. Blood leukocyte differential in Helicobacter pylori infection. Dig Dis Sci 1996; 41(7): 1332-6.

43. Nagata A, Sekiguchi N, Kurimoto M, Noto S, Takezako N. Significance of lymphocyte counts at diagnosis in the management of ITP: the relationship between lymphocyte counts and treatment success in $H$. pylori-infected patients. Int J Hematol 2015; 101(3): 268-72. 